\title{
Article \\ Food Habits and Lifestyle of Romanians in the Context of the COVID-19 Pandemic
}

\author{
Valentin Năstăsescu ${ }^{1,+}$, Magdalena Mititelu ${ }^{2, *,+} \mathbb{D}$, Tiberius Iustinian Stanciu ${ }^{3,+}$, Doina Drăgănescu 4, \\ Nicoleta Diana Grigore ${ }^{2,+}$, Denisa Ioana Udeanu $2,+\left(\mathbb{D}\right.$, Gabriela Stanciu ${ }^{5, *} \mathbb{D}$, Sorinel Marius Neacșu ${ }^{6, t}$, \\ Cristina Elena Dinu-Pîrvu ${ }^{1}$, Eliza Oprea ${ }^{7,+} \mathbb{D}$ and Manuela Ghica ${ }^{8}$
}

1 Department of Physical and Colloidal Chemistry, Faculty of Pharmacy, University of Medicine and Pharmacy Carol Davila, 020956 Bucharest, Romania; valentin.nastasescu@umfcd.ro (V.N.); cristina.dinu@umfcd.ro (C.E.D.-P.)

2 Department of Clinical Laboratory and Food Safety, Faculty of Pharmacy, University of Medicine and Pharmacy Carol Davila, 020956 Bucharest, Romania; diana-nicoleta.grigore@rez.umfcd.ro (N.D.G.); denisa.udeanu@umfcd.ro (D.I.U.)

3 Press Office, Ovidius University of Constanța, 900527 Constanța, Romania; tiberius.stanciu@365.univ-ovidius.ro

4 Pharmaceutical Physics and Informatics Department, Faculty of Pharmacy, Carol Davila University of Medicine and Pharmacy, 020956 Bucharest, Romania; doina.draganescu@umfcd.ro

5 Department of Chemistry and Chemical Engineering, Faculty of Applied Sciences and Engineering, Ovidius University of Constanța, 900527 Constanța, Romania

6 Proffesional Farma Line, 116 Republicii Street, 105200 Baicoi, Romania; sorinel.neacsu@pfarma.ro

7 Department of Organic Chemistry, Biochemistry and Catalysis, Faculty of Chemistry, University of Bucharest, 030018 Bucharest, Romania; eliza.oprea@g.unibuc.ro

8 Department of Biostatistics, Faculty of Pharmacy, University of Medicine and Pharmacy Carol Davila, 020956 Bucharest, Romania; manuela.ghica@umfcd.ro

check for updates

Citation: Năstăsescu, V.; Mititelu, M.; Stanciu, T.I.; Drăgănescu, D.; Grigore, N.D.; Udeanu, D.I.; Stanciu, G.; Neacșu, S.M.; Dinu-Pîrvu, C.E.; Oprea, E.; et al. Food Habits and Lifestyle of Romanians in the Context of the COVID-19 Pandemic. Nutrients 2022, 14, 504. https://doi.org/ $10.3390 /$ nu14030504

Academic Editor: Shaw Watanabe

Received: 24 December 2021

Accepted: 19 January 2022

Published: 24 January 2022

Publisher's Note: MDPI stays neutral with regard to jurisdictional claims in published maps and institutional affiliations.

Copyright: () 2022 by the authors Licensee MDPI, Basel, Switzerland. This article is an open access article distributed under the terms and conditions of the Creative Commons Attribution (CC BY) license (https:// creativecommons.org/licenses/by/ $4.0 /)$.
* Correspondence: magdalena.mititelu@umfcd.ro (M.M.); gstanciu@univ-ovidius.ro (G.S.)

$\dagger$ These authors contributed equally to this work.

\begin{abstract}
The pandemic caused by the SARS-CoV-2 virus has produced significant changes in sociocultural life, diet, and interpersonal relationships across the world's population. The present study aims to identify changes in lifestyle and diet among the Romanian population one year after the onset of the COVID-19 pandemic. An online questionnaire with 58 items (addressing the following aspects: socio-demographic and anthropometric data, current eating habits, and lifestyle changes) was distributed using institutional mailing lists and social media. A total number of 2040 respondents participated in the study, of whom 1464 were women, and 576 men. Among the respondents, 1598 came from urban areas and 442 from rural areas. The processing of the collected data showed significant changes in the behavior of the respondents caused by the pandemic situation with psychoaffective changes in some cases. The number of people who had anxiety, depression and nervousness increased by up to $20 \%$. The majority of respondents (over $57 \%$ ) were up to 30 years old, either students $(43.50 \%)$ or employees going to workplaces (33.20\%). Analyzing eating habits, we found that diet modification was needed to increase the daily consumption of fruits, vegetables, fish, and seafood. Regarding weight status during the pandemic, we noticed that $34.7 \%$ of normal-weight respondents said that they gained weight while $49.7 \%$ of overweight people and $52.5 \%$ of obese people said that they gained weight $(p<0.0001)$. Regarding psycho-emotional behavior, $11.81 \%$ of the surveyed women stated that they frequently had depressive states during the pandemic period and $11.63 \%$ of the men stated that they frequently presented depressive states during the pandemic $(p=0.005)$.
\end{abstract}

Keywords: COVID-19 pandemic; SARS-CoV-2; diet changes; lifestyle changes; social life changes; psycho-affective changes 


\section{Introduction}

The crisis generated by the SARS-CoV-2 virus requires solutions with joint efforts from all states to protect population health and reduce the damage to national economies. In order to avoid catastrophic outcomes for national health systems and reduce the number of casualties, many countries have initiated social distancing policies to slow the spread of the SARS-CoV-2 virus. The COVID-19 pandemic has caused all employees worldwide to suddenly experience significant changes, both in the family and in their professional activity, the most affected being low-wage workers without access to social protection [1-3].

The economic impact of the coronavirus crisis varies from one industrial sector to another and depends on a number of factors, including the possibility of adapting to supply chain disruptions, the existence of stocks or dependence on the capacity of production processes. The tourist ecosystem has also been severely affected by traffic and travel restrictions due to the coronavirus crisis [4-6].

For many children and parents, the COVID-19 pandemic has changed daily routines. As more and more families are facing social distancing, self-quarantine and the closure of schools and jobs, they may feel stressed. Stress occurs not only because of health concerns, but also because families have to deal with a new reality, when they have suddenly found themselves at home for several days with children whose daily routines were severely affected. Isolation at home and limited interactions with their peers make children anxious. The lack of outdoor activities could make them more agitated and frustrated, stressing their parents even more $[7,8]$.

In all countries of the world, in the conditions of isolation at home, limited contact with members of the social network, working from home, closed schools/universities, the lack of facilities for spending time and financial insecurity, family relationships have become increasingly strained, sometime reaching extreme manifestations [9-13].

The lockdown, travel restrictions, and economic problems have made people feel lonelier in 2020 than ever before. Moreover, a lack of exercise and increased compulsive eating during the pandemic has led to increased obesity among the population, with serious health implications [14-17].

Romania was facing a health crisis generated by the fourth wave of the COVID-19 pandemic. As of 4 October 2021, 1,274,119 confirmed cases of SARS-CoV-2 virus infection were reported in Romania, of which 1,130,791 (88.75\%) were cured patients and 37,677 (2.96\%) were deceased patients. Regarding the Vaccination Campaign, as of the same date 10,428,307 doses of SARS-CoV-2 virus vaccine were administered and 5,434,368 people were reported to be immunized, meaning $27.99 \%$ of the total population [18].

Despite all of the efforts made by the authorities, the vaccination campaign of the Romanian population did not make much progress; in addition, the government is reluctant to adopt the normative act regulating the implementation of the green COVID-19 certificate at work.

Regarding the support of the population for better access to basic foods, Romania, following the example of Poland, is preparing to take steps within the European Union to approve the reduction of value-added tax to zero for basic products (meat, eggs, products dairy products).

In the current context caused by the COVID-19 pandemic, the population is becoming more and more aware of the need to adopt a healthy lifestyle and a balanced diet, primarily to support the immune system. Strong immunity is the best barrier against virus infections, including those with the new coronavirus. The body's immunity is affected by a large number of factors. Stress diminishes the body's immune response to pathogens. Food quality is also an important factor that affects the body's reserves and endurance. The health of the body depends on the lifestyle that a person adopts. Factors that influence a healthy lifestyle are diet, hydration, sleep time and physical activity. The quality of sleep has an impact on both the state of health and the psyche. Therefore, sleep hours must be monitored, and a balanced sleep program is needed, without excesses and without radical changes. One way to strengthen the body's endurance is physical exercise, performed 
consistently. Moreover, exercise also contributes to maintaining a good mental tone. A healthy lifestyle includes following a program that includes three main meals each day, as well as eating healthy foods, rich in vitamins. Additionally, any excess should be avoided, especially when it comes to unhealthy foods or drinks [19-22].

Various clinical studies suggest the need to consume 20-30 different types of food during a week, particularly of plant origin. Food diversity compensates for nutrient deficiencies and reduces the toxic effect that excessive intake of natural or processed compounds from food can have. The intake of proteins, carbohydrates, lipids, vitamins and minerals must cover the body's energy needs and structural needs. The most important sources of essential amino acids (complete proteins) are milk, meat, eggs, and cheese. The portion of food must be modified to favor the variety of food, in order to cover the dietary needs of the individual [23-28].

Additionally, certain drugs affect the body's immunity. Repeated administration of antibiotics, steroid anti-inflammatory drugs and chemotherapy inhibits the immune system [29-31]. Prolonged exposure to toxic substances (air pollution, toxic work environment, various solvents, heavy metals) is another factor that affects the body's ability to detoxify, regenerate and revitalize [32-35].

The objective of the paper is to investigate the changes in lifestyle, eating habits and psycho-affective state among the Romanian population one year after the onset of the COVID-19 pandemic.

\section{Materials and Methods}

\subsection{Study Design}

Between 3 May and 6 June 2021, a study was conducted among the Romanian population based on a questionnaire disseminated online using the Google Forms web survey platform to identify changes in lifestyle and diet during the first year of the COVID-19 pandemic. The link for the online survey was shared through social media and the institutional mailing lists of students and professional organizations from Romania. Participants were also asked to share the link of a questionnaire with their colleagues and friends. The questionnaire contains 58 items that address the following aspects: socio-demographic data (age, sex, occupation, area of residence, occupation), anthropometric data (height, weight), eating habits, lifestyle and psycho-affective behavior before and during the pandemic. The final database was downloaded as a Microsoft Excel sheet.

The criterion for participation in the study was an age over 18 years. Participation in the study based on the questionnaire was entirely voluntary and anonymous. Respondents were informed from the beginning about the purpose of the study and asked for permission to use and publish the data. The anonymous nature of the web survey does not allow sensitive personal data to be traced in any way.

Individuals who agreed to participate were informed of the purpose of the study and were assured of the confidentiality of the results. Additionally, the completion of the questionnaire was in compliance with GDPR rules.

\subsection{Questionnaire Validation}

In order to finalize the questions and eliminate the ambiguities, the questionnaire was previously distributed to a group of 200 people aged 18 years and above, in the form of a test together with an additional form with 6 questions related to: clarity of questions in the questionnaire, understanding of the questions asked, the layout of the questionnaire (framing of the questions, the format and size of the letters), the time required to complete the questions in the questionnaire, the relevance of the questions in relation to the purpose of the questionnaire and suggestions for possible improvements to the questionnaire. By addressing it, the aim was to identify any ambiguity in the questions, an ensure the correct completion. The results of testing the pilot phase questionnaire were analyzed by a group of 10 experts for content validation and optimization. Content validity ratio (CVR), and content validity index (CVI) were calculated [36,37]. The necessity of items was 
assessed using a three-point scale and scores ranged between -1 (not necessary), 0 (useful but not essential), and +1 (essential). The relevance and clarity of each item were also calculated using a four-point Likert scale: (1) not relevant/clear, (2) slightly relevant/clear and needs revision, (3) relevant/clear and needs minor revision, and (4) very relevant/clear. Irrelevant items were removed based on expert opinions and modifications were made to the remaining items to make them more accurate and increase clarity.

Cronbach's $\alpha$ coefficient was used to determine the internal consistency of the questionnaire. The value of Cronbach's $\alpha$ for our questionnaire came out to be 0.86 , which suggests a good internal consistency and also that the scale in this study is reliable [38].

Finally, the final form of the questionnaire, presented in Appendix A, was designed.

\subsection{Statistical Analysis}

All the categorical characteristics from our study were analyzed qualitatively and were expressed as a percentage (\%) and numbers ( $n$ ). Additionally, the numerical characteristics were transformed into qualitative variables (such as age and BMI variables) and expressed by percentages $(\%)$ and numbers $(n)$.

The Pearson's chi-square $\left(\chi^{2}\right)$ test was used to analyze the relationship between the categorical variables and thus to find patterns of dietary changes. Additionally, we used two-way analysis of variance (robust ANOVA) and multinomial logistic regression analyses were performed to analyze the factors (gender, age group, BMI group) that influenced the odds of assignment to the healthy diet, moderate healthy diet and unhealthy diet $[39,40]$. In order to analyze the adherence of the respondents to a healthy diet, the answers from questions 7-10 and 12-18 of the questionnaire were quantified by giving a score from 1 to 5 . A healthy diet consisted of a daily intake of fruits and vegetables, a low consumption of saturated fats and the avoidance of the consumption of hydrogenated fats, a consumption of foods rich in valuable nutrients (meat, eggs, fish, seafood, dairy products) according to the body's energy needs, a low alcohol consumption, and moderate consumption of sweets and bread. The consumption of unhealthy foods or the lowest consumption of healthy foods rich in valuable nutrients was scored with 1, and 5 scored the consumption of the healthiest foods or the high frequency of the consumption of foods rich in valuable nutrients. Based on these answers, we formed a raw score that could then be scaled into a T-score (standardized) with a mean of 50.0 and standard deviation of 10.0 [41]. Finally, the results were divided into three categories: scores under 33.3 became an unhealthy diet, over 66.6 became a healthy diet and the rest of the values were framed as a moderately healthy diet. The results of multinomial logistic regression analyses are expressed as risk ratio $(\mathrm{RR})$ and standard errors.

The dependent variable is "healthy eating", and the reference group is "moderate healthy diet".

Independent variables are:

1. Gender where the reference group is "female";

2. BMI group where the reference group is "normal weight";

3. Age group where the reference group is young people in the range "[18-30]".

For all statistical analyses, $p<0.05$ was considered significant. Statistical analysis was implemented using the open-source software $R$ ( $R$ version 4.1.1) [42].

\section{Results}

\subsection{Socio-Demographic and Anthropometric Data}

Following the dissemination of the questionnaire in the online environment, a total of 2054 responses were obtained, of which 2040 were valid answers (answers with incorrect anthropometric data were eliminated). Of the respondents, $71.61 \%$ were women (1464) and $28.39 \%$ men (576). According to the registered answers, 1598 (78.14\%) of the persons who completed the questionnaire lived in urban areas and $442(21.86 \%)$ in rural areas. The anthropometric data (weight and height) were used to calculate BMI by using the Quetelet equation (body mass $(\mathrm{kg}) /$ height $\left(\mathrm{m}^{2}\right)$ ) and interpreted according to the criteria of 
the World Health Organization [43]. Most of those who participated in the survey were normal weight (57.78\%), $7.25 \%$ were underweight, $24.97 \%$ were overweight and $9.98 \%$ were obese [44]. The sociodemographic and lifestyle characteristics of participants are presented in Table 1.

Table 1. Socio-demographic and lifestyle characteristics of participants $(n=2040)$.

\begin{tabular}{|c|c|c|}
\hline Characteristics & $n$ & $\%$ \\
\hline \multicolumn{3}{|l|}{ Gender } \\
\hline Male & 576 & 28.3 \\
\hline Female & 1464 & 71.6 \\
\hline \multicolumn{3}{|l|}{ Age (years) } \\
\hline $18-30$ & 1166 & 57.5 \\
\hline $31-50$ & 684 & 33.5 \\
\hline $51-65$ & 155 & 7.6 \\
\hline$>65$ & 36 & 1.8 \\
\hline \multicolumn{3}{|l|}{ Residence areas } \\
\hline Urban areas & 1598 & 78.1 \\
\hline Rural areas & 442 & 21.9 \\
\hline \multicolumn{3}{|l|}{ Employment status } \\
\hline Unemployed & 20 & 1.0 \\
\hline Socially assisted & 0 & 0.0 \\
\hline Retired & 65 & 3.2 \\
\hline Student & 888 & 43.5 \\
\hline Housewife & 43 & 2.1 \\
\hline I am going to work as usual & 677 & 33.2 \\
\hline Working/studying from home & 122 & 6.0 \\
\hline $\begin{array}{l}\text { Hybrid work (teleworking and } \\
\text { commuting) }\end{array}$ & 180 & 8.8 \\
\hline $\begin{array}{l}\text { I had my job temporarily suspended due to the pandemic } \\
\text { Body mass index (BMI) }\end{array}$ & 42 & 2.1 \\
\hline Normal limits (18.5-24.9) & 1179 & 57.7 \\
\hline Overweight category (25-29.9) & 509 & 24.9 \\
\hline Underweight category $(<18.5)$ & 148 & 7.2 \\
\hline Obese $(\geq 30)$ & 204 & 9.9 \\
\hline \multicolumn{3}{|l|}{ Weight change during COVID-19 } \\
\hline Weight is stable & 811 & 39.8 \\
\hline Lost weight & 328 & 16.1 \\
\hline Gained some weight & 784 & 38.4 \\
\hline Do not know & 117 & 5.7 \\
\hline \multicolumn{3}{|l|}{ Appetite change during COVID-19 } \\
\hline No & 1065 & 52.2 \\
\hline Less appetite & 309 & 15.1 \\
\hline More appetite & 666 & 32.6 \\
\hline \multicolumn{3}{|l|}{ Smokers during COVID-19 } \\
\hline Yes & 713 & 35.0 \\
\hline No & 1327 & 65.0 \\
\hline \multicolumn{3}{|l|}{ Sports practitioners during COVID-19 } \\
\hline Yes & 1272 & 62.4 \\
\hline No & 768 & 37.6 \\
\hline \multicolumn{3}{|l|}{ Alcohol consumer } \\
\hline Very rarely or not at all & 1443 & 70.7 \\
\hline Daily & 69 & 3.3 \\
\hline Moderate & 528 & 26.00 \\
\hline \multicolumn{3}{|l|}{ Quarantined due to COVID-19 infection } \\
\hline Yes & 539 & 26.4 \\
\hline No & 1501 & 73.6 \\
\hline
\end{tabular}


Table 1. Cont.

\begin{tabular}{ccc}
\hline Characteristics & $\boldsymbol{n}$ & $\mathbf{\%}$ \\
\hline Quality of life changed during COVID-19 & & \\
Improved & 245 & 12.0 \\
No changed & 491 & 24.1 \\
Deteriorated & 1304 & 63.9 \\
Diet & & \\
Healthy diet & 102 & 5.0 \\
Moderately healthy diet & 1836 & 90.0 \\
$\quad$ Unhealthy diet & 102 & 5.0 \\
\hline
\end{tabular}

One year after the onset of the pandemic, $39.8 \%$ of respondents said they had maintained a constant body weight, $38.4 \%$ said they had gained weight and $32.6 \%$ said they had an increased appetite. Of the participants in the questionnaire, $62.4 \%$ stated that they engaged in sports during the pandemic and $26.4 \%$ stated that they were quarantined due to infection with the novel coronavirus. We noted a negative change in the quality of life of the population caused by the COVID-19 pandemic; most respondents said that living standards deteriorated during the pandemic (63.9\%) and only $12 \%$ said that life improved (Table 1 ). Of the people surveyed, $38.1 \%$ said they played sports at home during the pandemic, $22.5 \%$ outdoors and only $6 \%$ in the gym. Regarding the frequency of sports activities during the pandemic, the percentage of those who did not exercise at all, or that exercised slightly or very rarely, increased and the percentage of those who used to do sports daily before the pandemic decreased. Thus, $13.4 \%$ of respondents stated that they exercised daily during the pandemic and $15.9 \%$ stated that they used to exercise daily before the pandemic, while $26.8 \%$ stated that they exercised very rarely during the pandemic (compared with $25.6 \%$ before the pandemic) and $37.6 \%$ that they did not play sports at all during the pandemic (compared with $34.1 \%$ before the pandemic). There was a tendency towards a sedentary lifestyle which intensified in the pandemic.

\subsection{Current Eating Habits}

From the analysis of the data presented in Table 2, a higher tendency among men to consume foods with a lower nutritional value was noticed compared with women. The majority of respondents preferred to consume foods with moderate nutritional value and only a small percentage, less than $6 \%$, frequently consumed foods with high nutritional value. According to the answers, the main type of used dietary fat was sunflower oil ( $63 \%$ of respondents said they use it the most when cooking); in general, most respondents consumed only one serving of vegetables and fruits a day, $65 \%$ of respondents stated that they consumed poultry meat the most, $42.5 \%$ consumed fish and seafood very rarely or not at all and $41 \%$ only once a week, $28.4 \%$ consumed sweets and pastries daily and only $15.8 \%$ very rarely or not at all, and $40 \%$ consumed dairy products daily. Related to food consumption, $27.2 \%$ of respondents said they ate excessively during the pandemic and $30 \%$ of respondents said that during the pandemic they consumed healthier food. Culinary preferences were dominated by home-cooked food $(79.9 \%)$, and only $21.5 \%$ of respondents declared they consumed ordered food and served at home.

Table 2. Adherence to a healthy diet according to gender in the pandemic time.

\begin{tabular}{ccc}
\hline Variables & $\boldsymbol{n}$ & $\mathbf{\%}$ \\
\hline Gender-diet & & \\
Male-healthy diet & 18 & 3.1 \\
Male-moderately healthy diet & 515 & 89.4 \\
Male-unhealthy diet & 43 & 7.4 \\
Female-healthy diet & 81 & 5.5 \\
Female-moderately healthy diet & 1328 & 90.7 \\
Female-unhealthy diet & 55 & 3.7 \\
\hline
\end{tabular}


According to the results of logistic regression analyses, presented in Table 3, we noticed a higher adherence to a healthy diet for older age groups compared with younger respondents (older age groups had higher RR values for a healthy diet compared to younger age groups, but they were not statistically significant). At the same time, the logistic regression model confirms a lower adherence of male respondents to a healthy diet compared with female respondents.

Table 3. Multinomial logistic regression expressed by risk ratio and standard error.

\begin{tabular}{ccc}
\hline & \multicolumn{2}{c}{ Dependent Variable } \\
& Healthy Diet (1) & Unhealthy Diet (2) \\
\hline \multirow{2}{*}{ Age Group 31-50 } & 1.176 & 0.708 \\
& $(0.232)$ & $(0.249)$ \\
\hline \multirow{2}{*}{ Age Group 51-65 } & 1.302 & $0.309 *$ \\
& $(0.393)$ & $(0.611)$ \\
\hline \multirow{2}{*}{ Age Group $>65$} & 1.496 & 0.304 \\
& $(0.760)$ & $(1.033)$ \\
\hline Gender Male & $0.584^{*}$ & $1.948^{* * *}$ \\
& $(0.275)$ & $(0.224)$ \\
\hline \multirow{2}{*}{ BMI Group 1 Underweight } & 0.470 & 1.724 \\
BMI Group 3 Overweight & $(0.526)$ & $(0.365)$ \\
\hline BMI Group 4 Obese & 0.730 & 1.320 \\
& $(0.278)$ & $(0.257)$ \\
\hline Constant & 0.854 & 1.380 \\
& $(0.365)$ & $(0.374)$ \\
\hline Akaike Inf. Crit. & $0.063 * * *$ & $0.043 * * *$ \\
& $(0.163)$ & $(0.182)$ \\
\hline$<0.1 ; * * *<0.01$. & 1572.672 & 1572.672 \\
\hline
\end{tabular}

After processing the data, we observed that the majority of underweight and normalweight persons were female respondents, while obese people were mainly male respondents (Figure 1). Regarding the tendency to increase body weight during the pandemic, we noticed that $34.7 \%$ of normal weight respondents said that they gained weight, while $49.7 \%$ of overweight people and $52.5 \%$ of obese people said that they gained weight $(p<0.0001)$.

Regarding alcohol consumption, the respondents were divided into five groups according to the frequency of consumption: in group 1 were included the people who consumed alcoholic beverages the most frequently (one or more daily servings), while in group 5 were persons who consumed alcoholic beverages very rarely or not at all (Figure 2). We found that females who consumed alcohol the most often were of normal weight, while males who consumed alcohol the most often were from obese people $(p=0.0002)$. A high alcohol content of alcoholic beverages is correlated with a high caloric intake. In the present study, we could presume that either normal weight people consume low-alcohol drinks daily and in small quantities, or they were very active people so the additional caloric intake of alcohol was not excessive.

Thus, the restrictive measures imposed by the authorities reduced the infection rate, but the psycho-emotional pressure during the pandemic had a negative impact on the physical shape of the population and increased the obesity rate and therefore, the number of vulnerable people (Figure 3a).

From the analysis of the answers related to the appetite changes during the pandemic period (Figure 3b), we found that $32.4 \%$ of the normal-weight people stated that they had an increase in appetite, $33.6 \%$ of the overweight people and $39.2 \%$ of the obese people $(p<0.0001)$. 


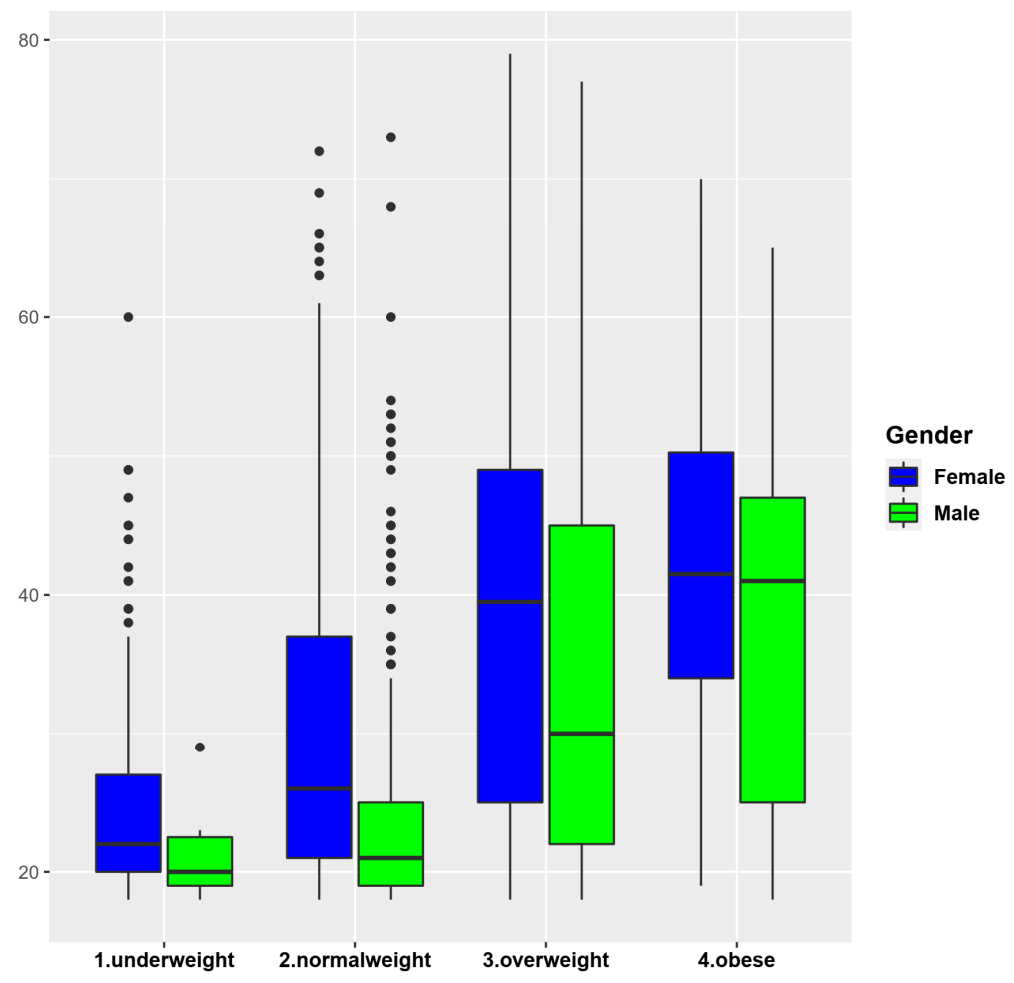

Figure 1. BMI according to gender and age.

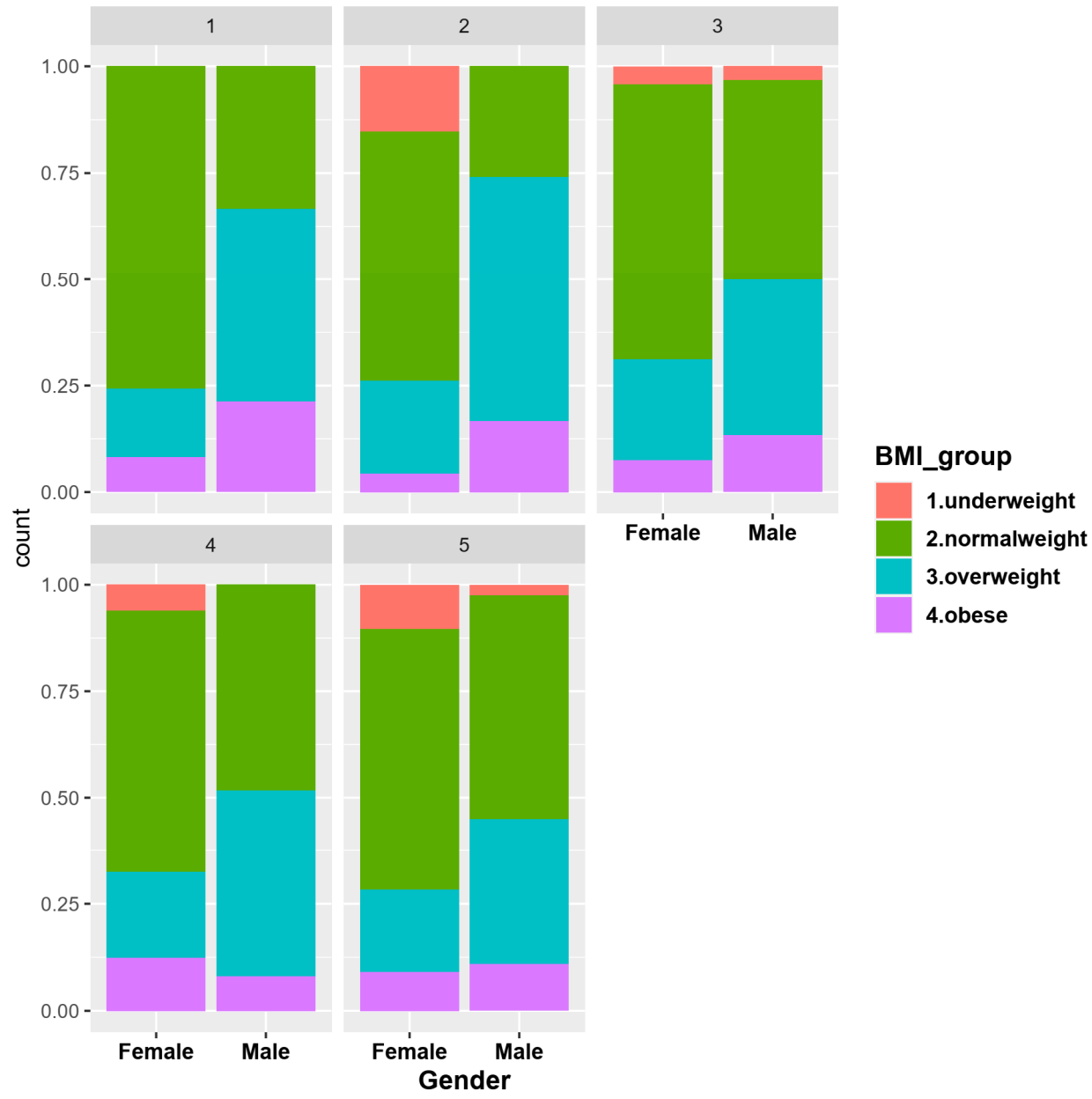

Figure 2. Alcohol consumption according to BMI and gender. 


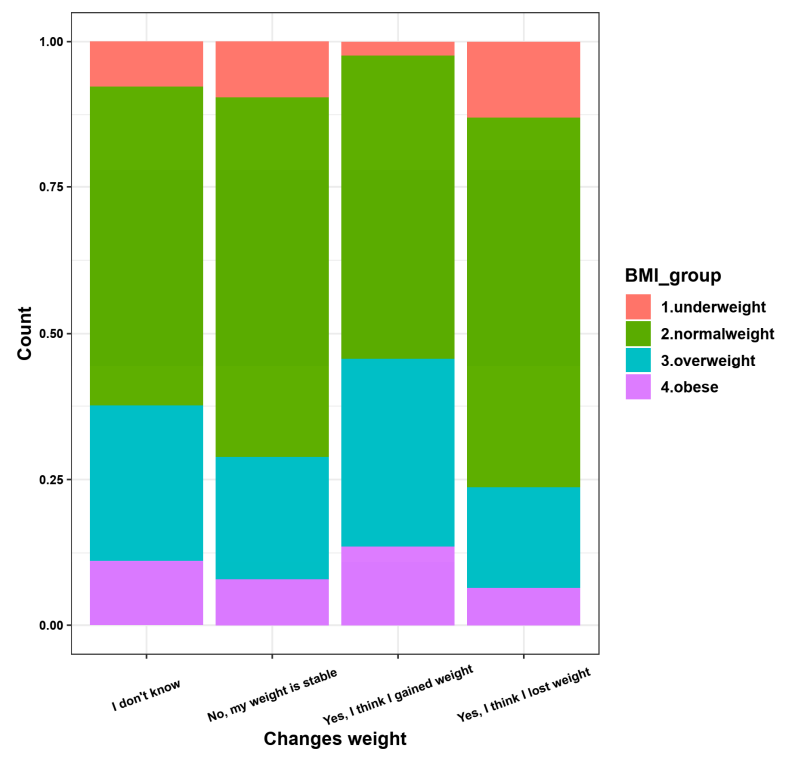

(a)

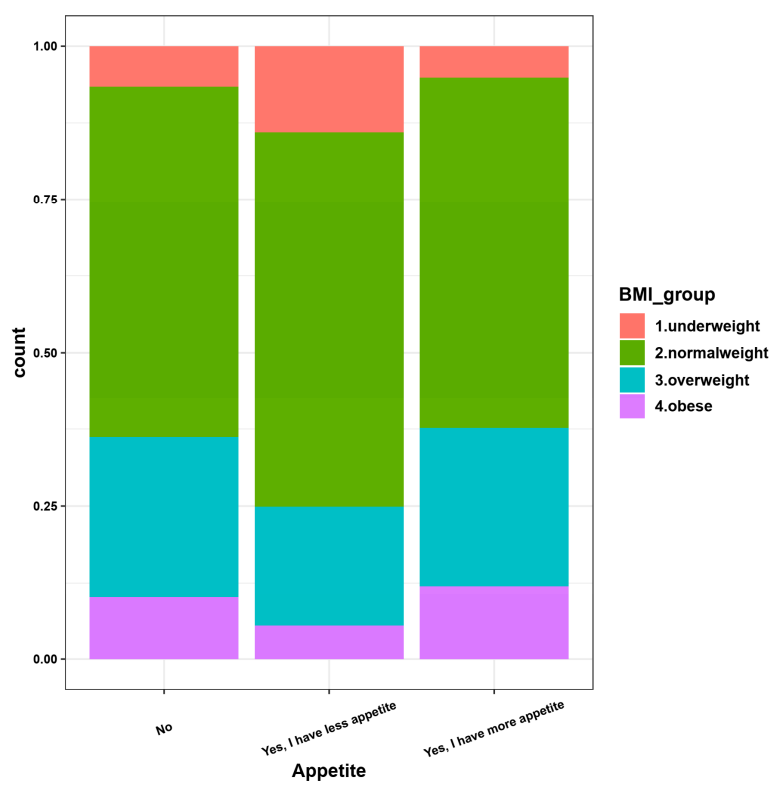

(b)

Figure 3. Perceptions regarding the changes in BMI during pandemic (a) and appetite changes (b) during pandemic according to BMI.

\subsection{Lifestyle and Psycho-Affective Changes}

Regarding a request for psychologist advice during the pandemic, only $8.13 \%$ of female respondents $(p<0.02)$ and $5.2 \%$ of male respondents responded positively (Figure $4 a$ ).

The pandemic smokers were divided into four groups: in group 1 were included those who reported smoking daily, in group 2 those who smoked 2-3 times a week, in group 3 those who smoked occasionally and in group 4 non-smokers (Figure $4 \mathrm{~b}$ ). The processed data show that $23.77 \%$ of female respondents stated that they smoked daily and $35.41 \%$ of male respondents $(p<0.0001)$. From the data processing we found that in general, in all four groups, the most affirmative responses related to the frequent presence of nervousness in the pandemic period were recorded among female respondents.

Depending on the duration of sleep during the pandemic period, the respondents were divided into four groups (Figure 4c): in group 1 were included people who said they had frequent insomnia ( $7.3 \%$ of females and $4.68 \%$ of males in the group), group 2 included people who said they slept less than seven hours a night, group 3 included people who said they slept between 7 and $9 \mathrm{~h}$ a night $(61.47 \%$ of females and $56 \%$ of males in the group) and group 4 included people who said they slept more than $9 \mathrm{~h}$ a night $(p=0.0002)$. From the analysis of the recorded answers, we found that the people who declared that they presented frequent states of fatigue during the pandemic period were mainly from the female respondents and especially from the groups of those who rested either too much or too little during the night. Overall, $40.23 \%$ of female respondents stated that they frequently experienced fatigue during the pandemic and $24.82 \%$ of male respondents stated that they frequently had fatigue $(p<0.0001)$.

Regarding psycho-emotional behavior during the pandemic period (Figure $4 \mathrm{~d}$ ), $23.63 \%$ of the female respondents stated that they had frequent states of anxiety and among the male respondents $12.67 \%$ stated that they had frequent states of anxiety; $11.81 \%$ of the women surveyed stated that they frequently had depressive states during the pandemic period and $11.63 \%$ of the men stated that they frequently presented depressive states during the pandemic $(p=0.005)$. Less than half of the people who frequently presented anxiety and depression sought the advice of specialists. Additionally, from the answers received, we found that the percentage of people who often had anxiety, depression, and nervousness increased during the pandemic by up to $20 \%$. 


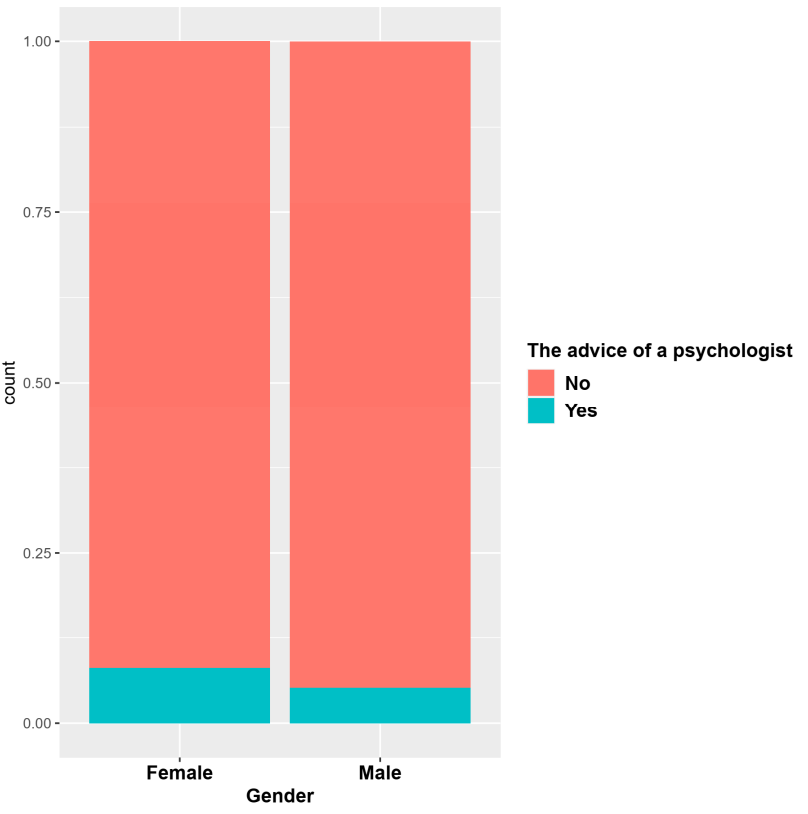

(a)

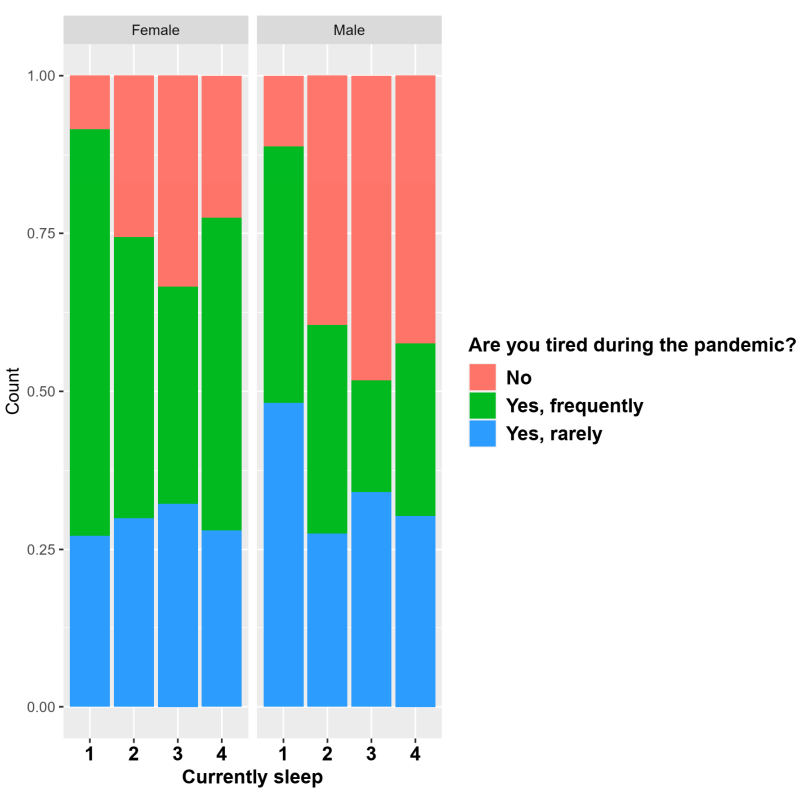

(c)

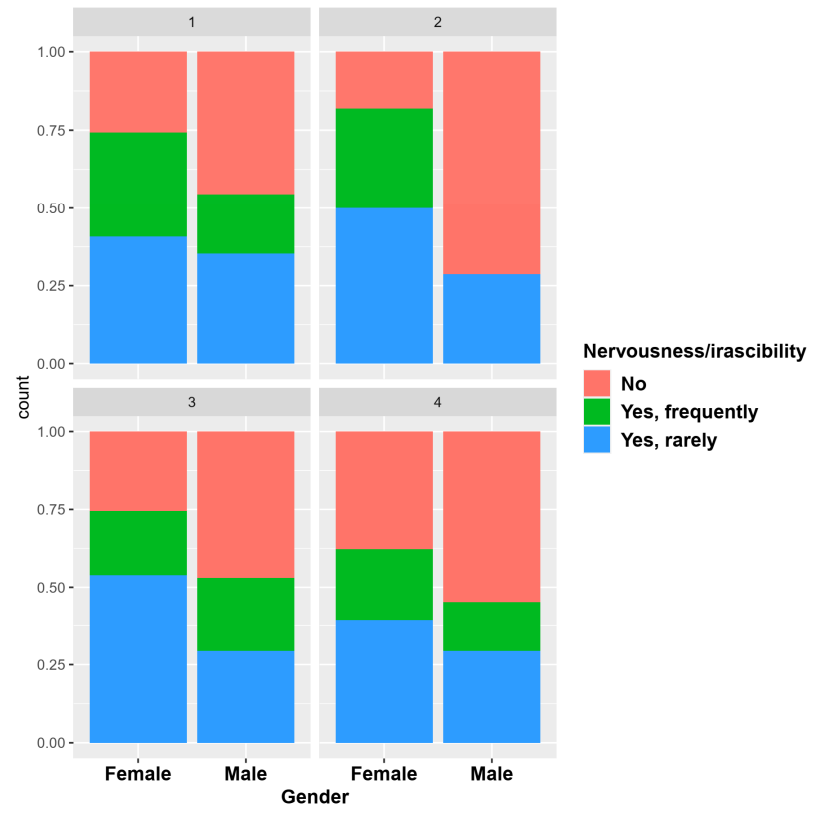

(b)

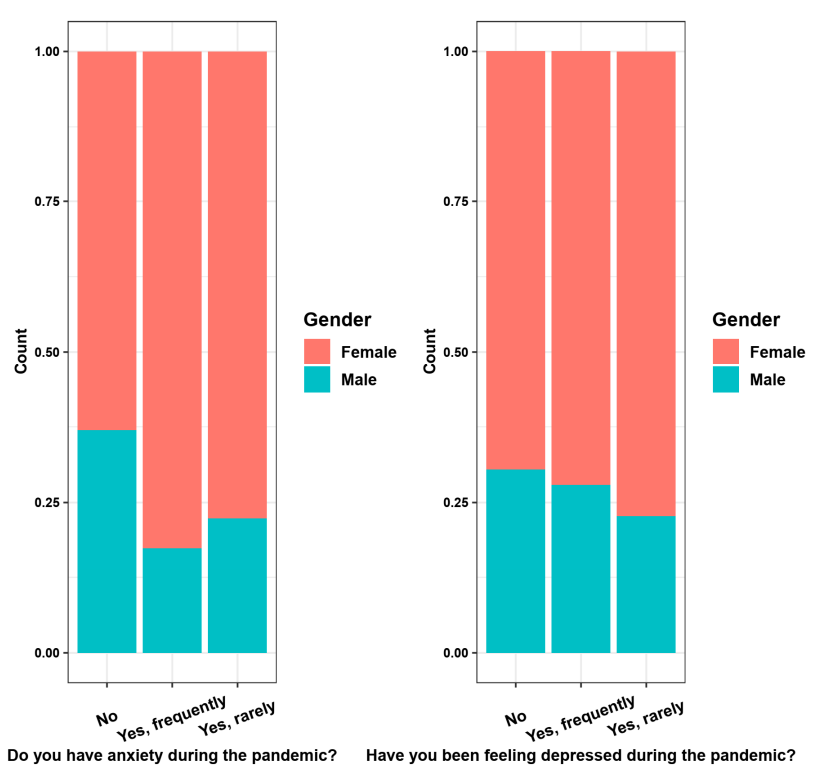

(d)

Figure 4. Lifestyle and psycho-affective changes. Persons requiring psychologist advice according to gender (a); smokers according to gender and nervousness/irascibility (b); tiredness related to sleeping habits according to gender (c); anxiety/depression according to gender (d).

From the collected data it was noted that $47.47 \%$ of females said they did not yet intend to be vaccinated against COVID-19, while $26 \%$ said they had been vaccinated with one or two doses $(p<0.0001) ; 37 \%$ of males participating in the survey said they did not currently intend to be vaccinated and $25 \%$ said they had been vaccinated with one or two doses (Figure 5a). 


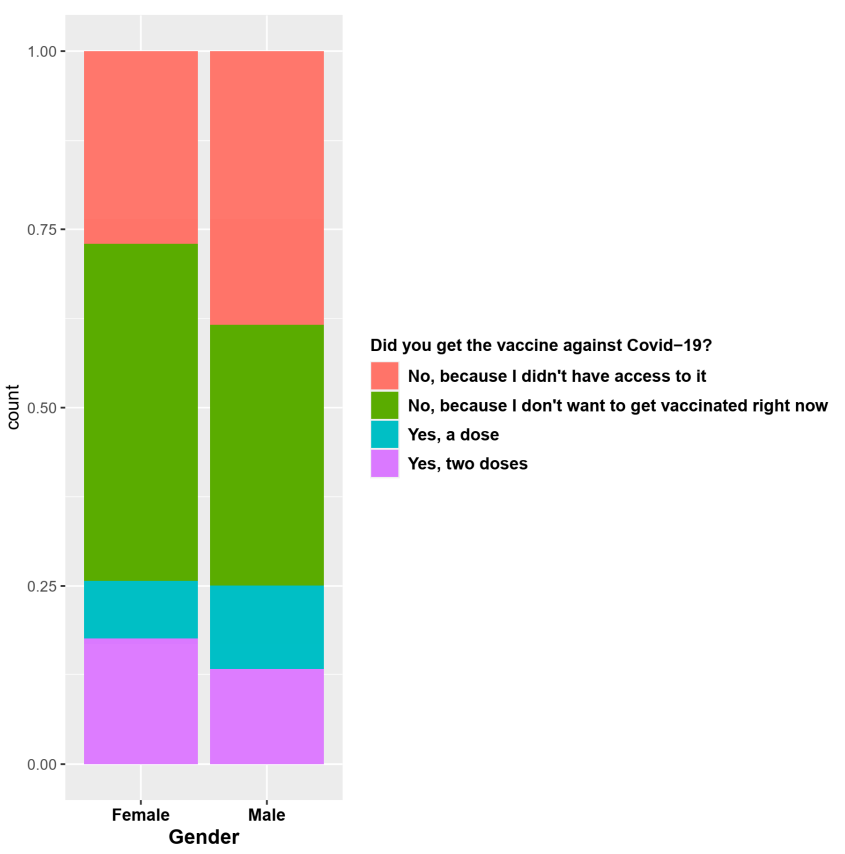

(a)

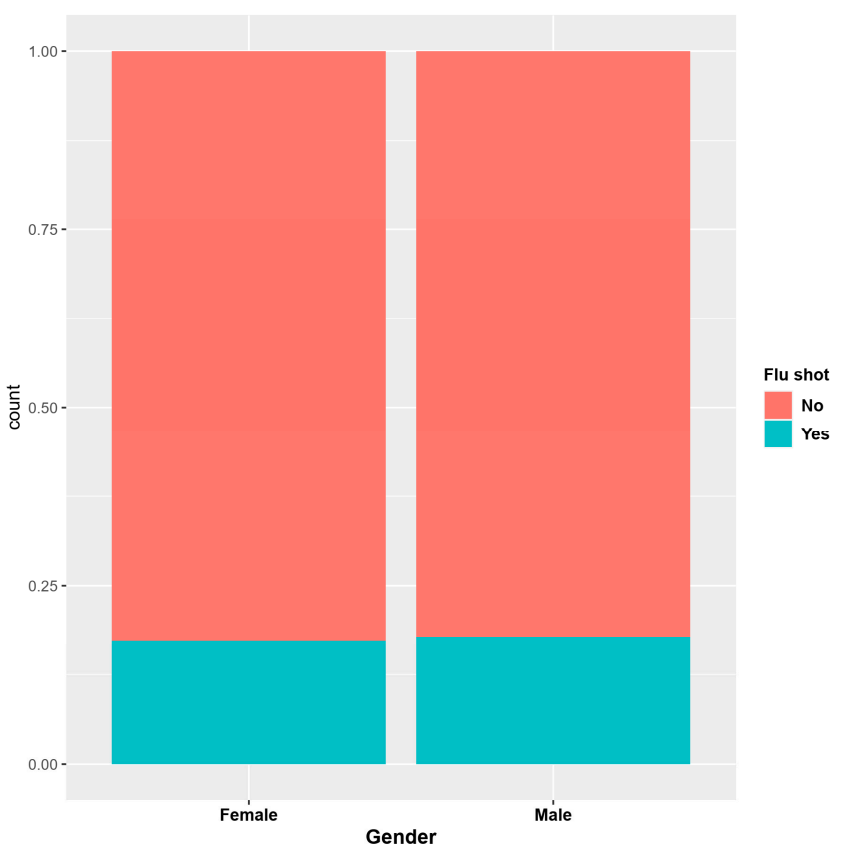

(b)

Figure 5. Vaccination among individuals according to gender: COVID-19 (a) and flu (b).

Regarding the flu vaccination, $17.34 \%$ of female respondents $(p=0.758)$ and $18.05 \%$ of male respondents said they got the flu vaccine (Figure $5 b$ ).

Among the most consumed food products in the pandemic compared with the previous period, according to the answers in the questionnaire, were: fresh fruits and vegetables, sweets, coffee and tea, homemade bread and pastries, and dairy products (Figure 6).

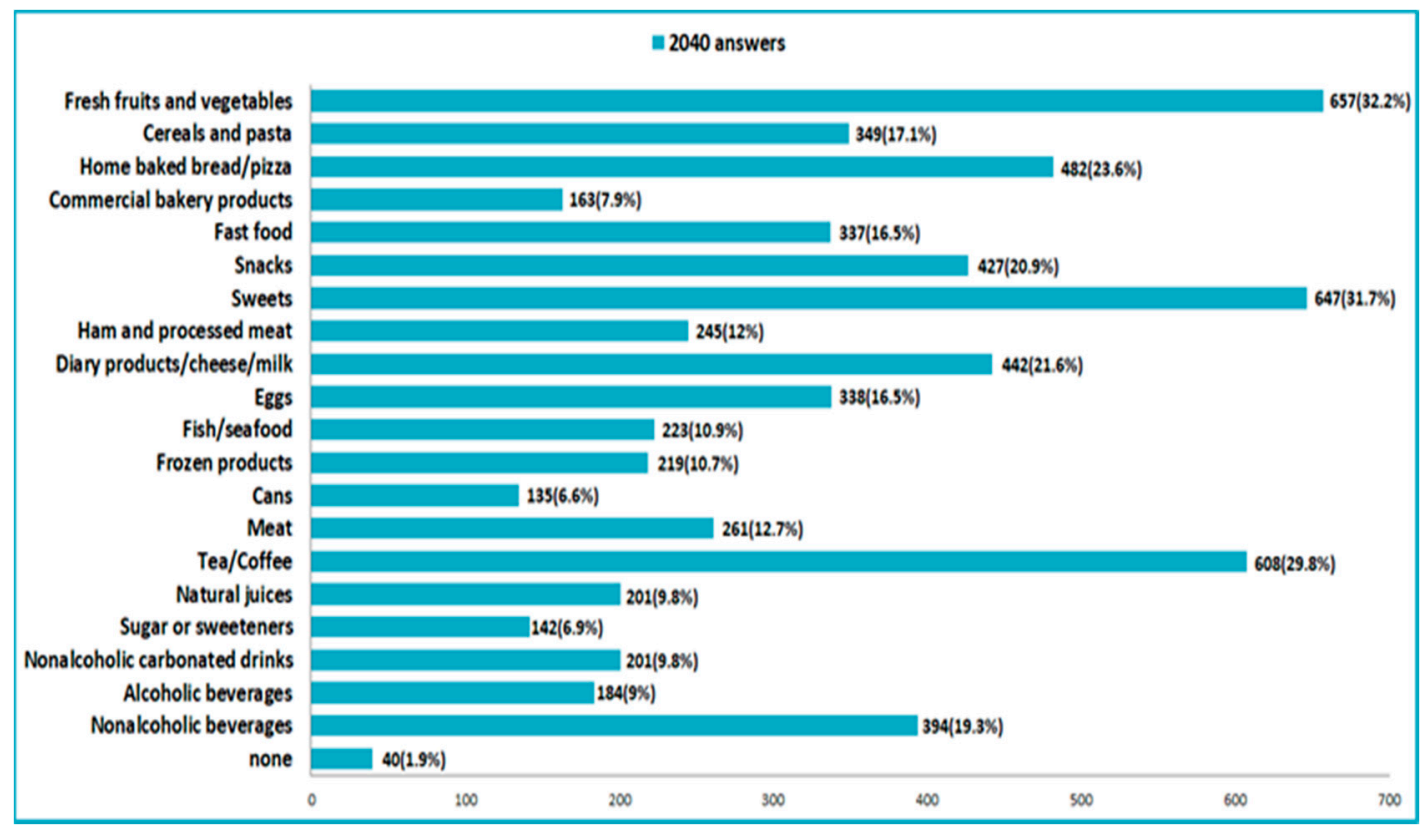

Figure 6. Food consumed more in the pandemic time.

On the other hand, among the least consumed food products in the pandemic compared with the previous period were fast food products and snacks, industrial bakery products and soft drinks (Figure 7). 


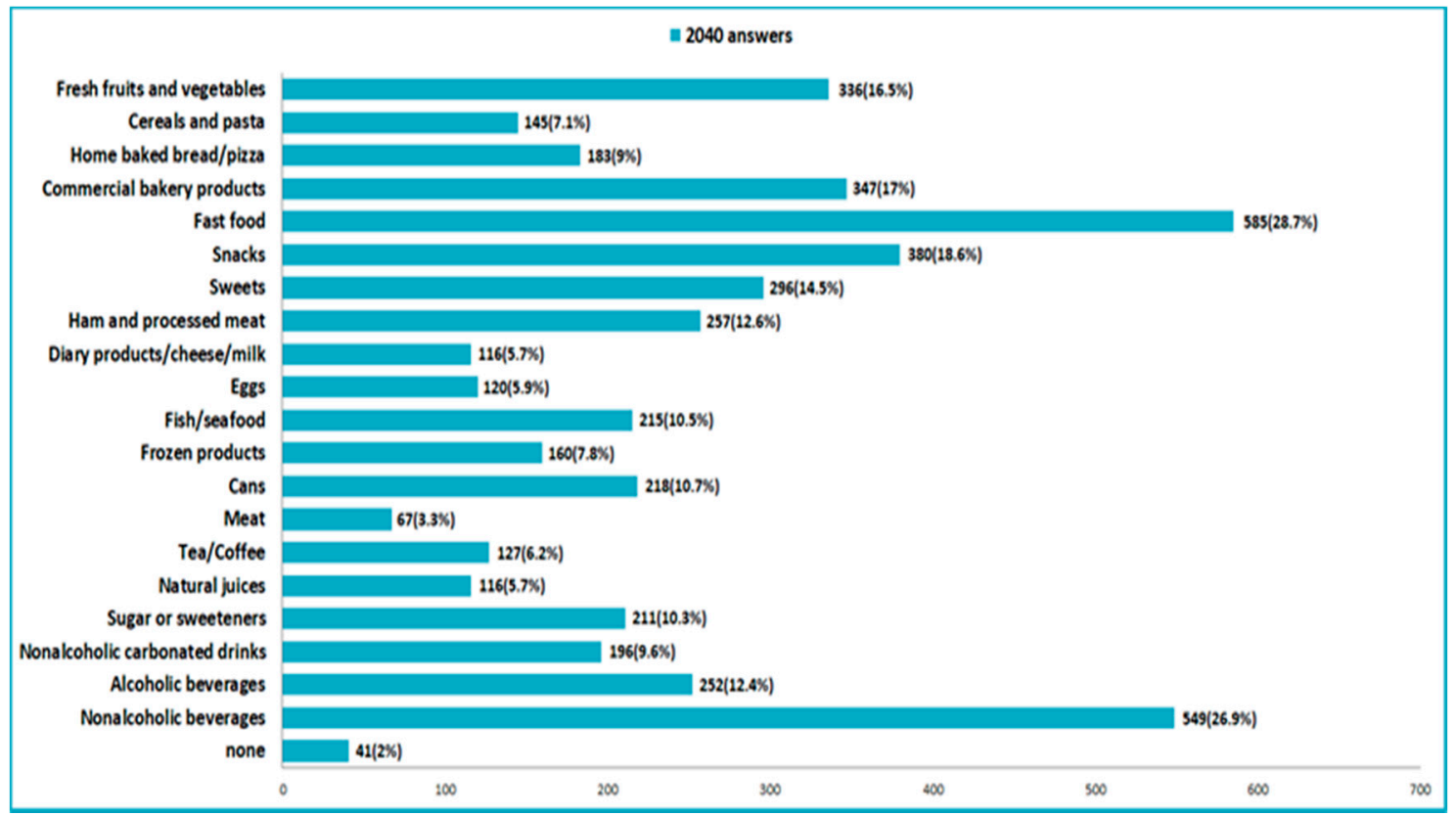

Figure 7. Food consumed less in the pandemic time.

During the pandemic period, $13.8 \%$ of the respondents stated that they added one or more main meals, $15.6 \%$ added one or more snacks between meals and $57.5 \%$ stated that they consumed between one and two liters of water per day.

The purchase of food and household products was mainly made from supermarkets $(68.5 \%)$ and shops near the house. Although the majority of respondents came from young and active people, we found that only a small percentage (19.9\%) said they bought products online (Figure 8).

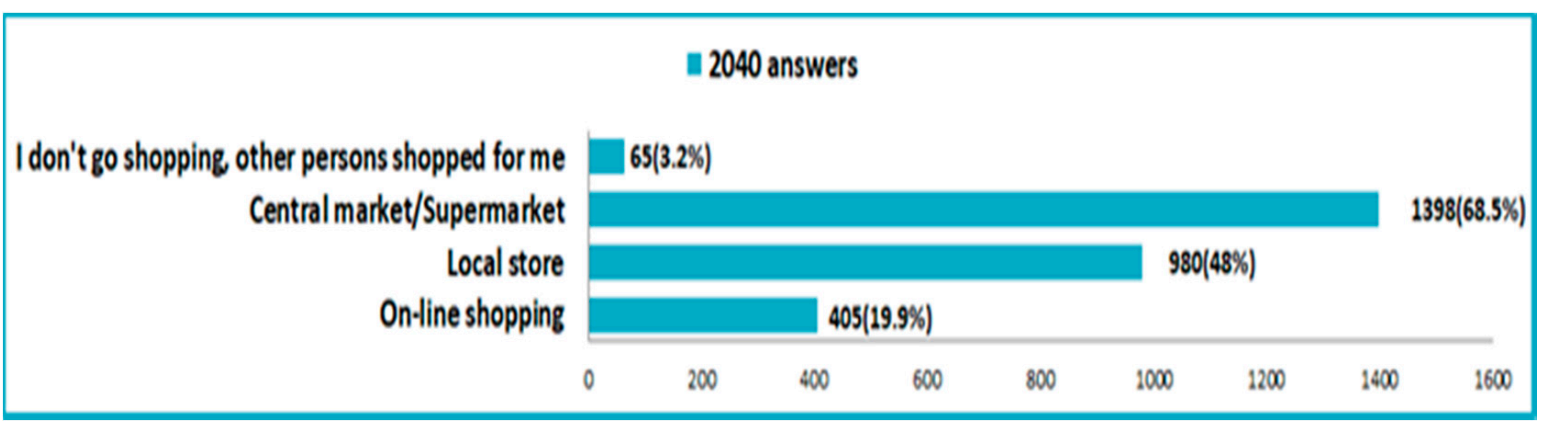

Figure 8. Ways of purchasing food and household products in the pandemic time.

Among the most purchased products during the pandemic period were: staple foods (sugar, flour, rice, oil, water, bread, pasta), vegetables and fruits, disinfectants and cleaning products, meat and sausages (Figure 9). Related to the decision to buy food $75.1 \%$ of the respondents stated that when purchasing a food product, they had taken into account mainly the quality and nutritional value.

Regarding the quality of life during the pandemic, $57.9 \%$ of the respondents stated that it was depreciated due to social distance. In fact, $74.7 \%$ respondents said that they lacked freedom of movement and $63.3 \%$ had difficulties in communication with family and friends (Figure 10). Among the behavioral changes produced by the COVID-19 pandemic, we particularly noted: monitoring health $(30.3 \%)$ and adopting a more understanding attitude towards others $(28.3 \%)$. However, there were also people who stated that they were isolated from others $(18.3 \%)$. 


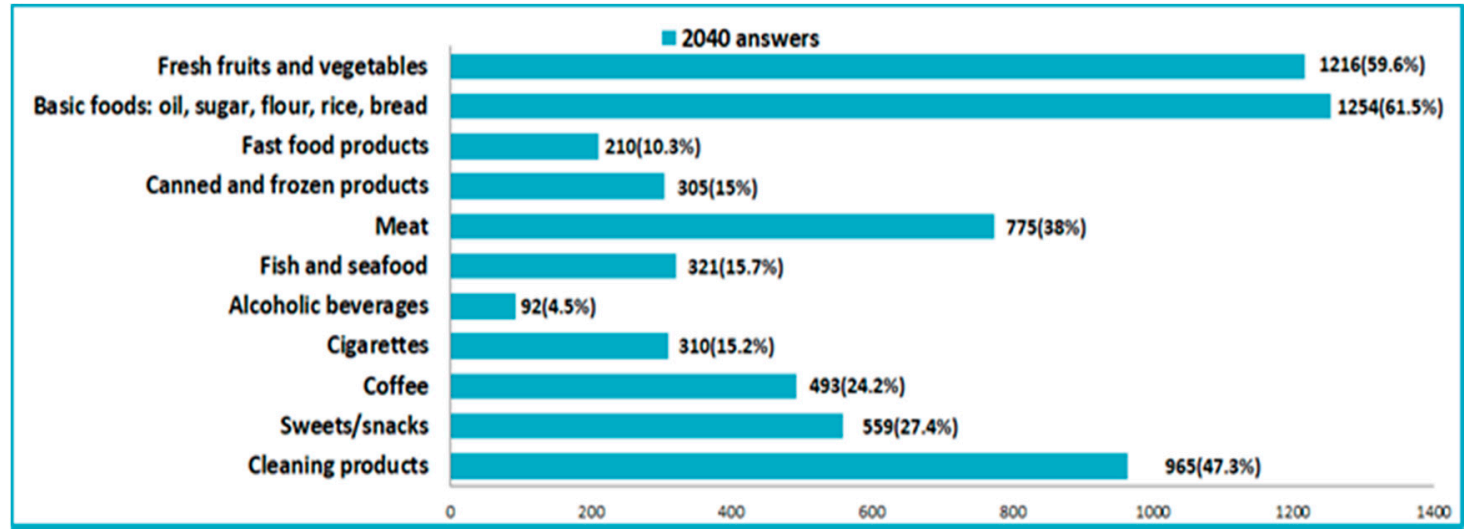

Figure 9. Products frequently purchased in the pandemic time.

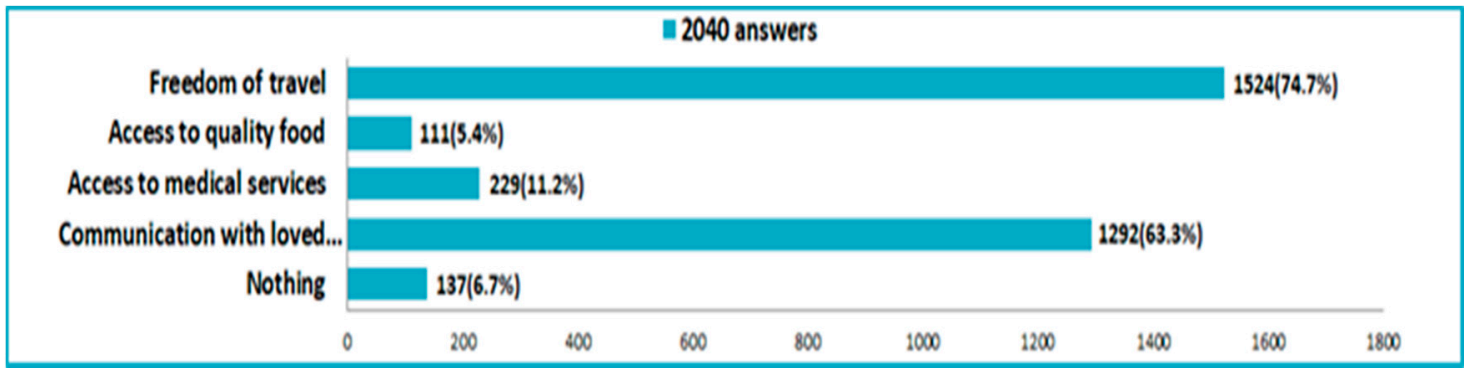

Figure 10. Deficiencies caused by the pandemic restrictions.

The way of spending the holidays also underwent major changes; $49.3 \%$ of the respondents stated that they did not go on vacation and $38.9 \%$ said that they traveled much less than in the period before the pandemic.

The majority of respondents $(61.7 \%)$ said they were clinically healthy (Figure 11$)$. Of the 2040 who answered the questions, 315 (15.4\%) stated that they did not know if they suffered from any disease, which means that they were not used to regularly monitoring their health. Only 5\% of those surveyed stated that they were obese but after the processing of anthropometric data we found that the percentage of obese participants was double (Figure 11, Table 1), which means that half of them had not realized that they were not normal weight. During the current pandemic context, $64.8 \%$ of respondents said that they feared more for the health of those close to them and only $25.9 \%$ said that they feared for their health.

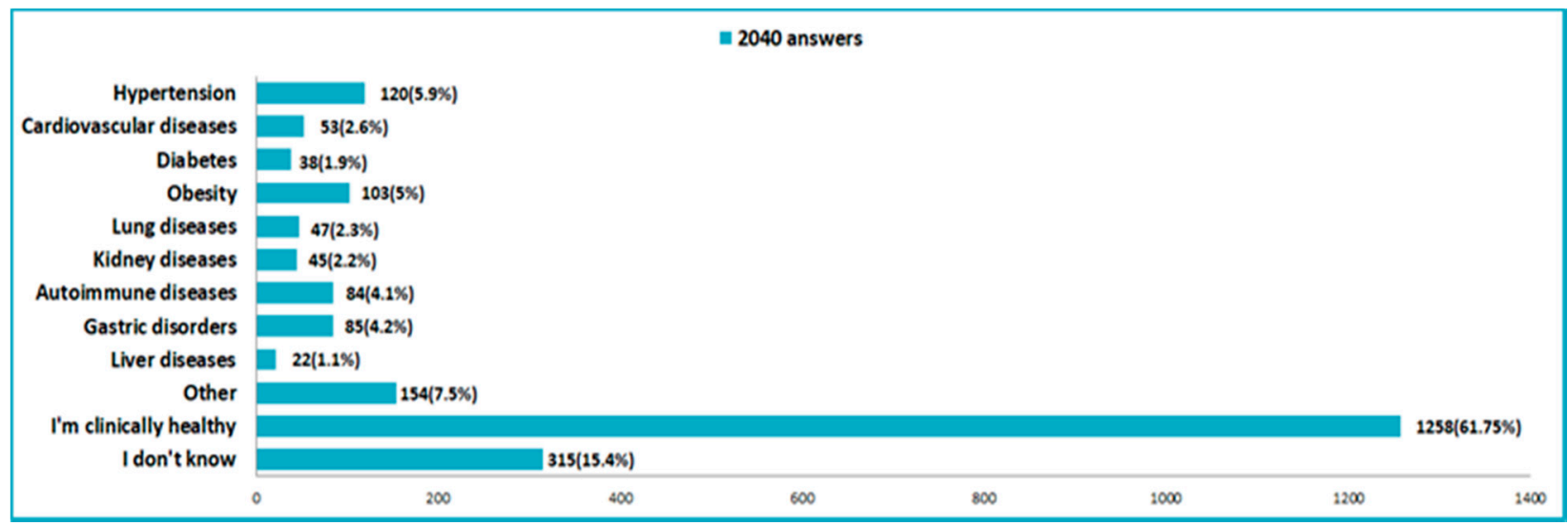

Figure 11. Distribution of chronic diseases of respondents in the pandemic time. 
During the pandemic $75.4 \%$ of respondents said they spent most of their free time watching movies and TV shows (Figure 12). Among the favorite ways to spend free time during the pandemic were meetings with family or friends, reading and outdoor activities.

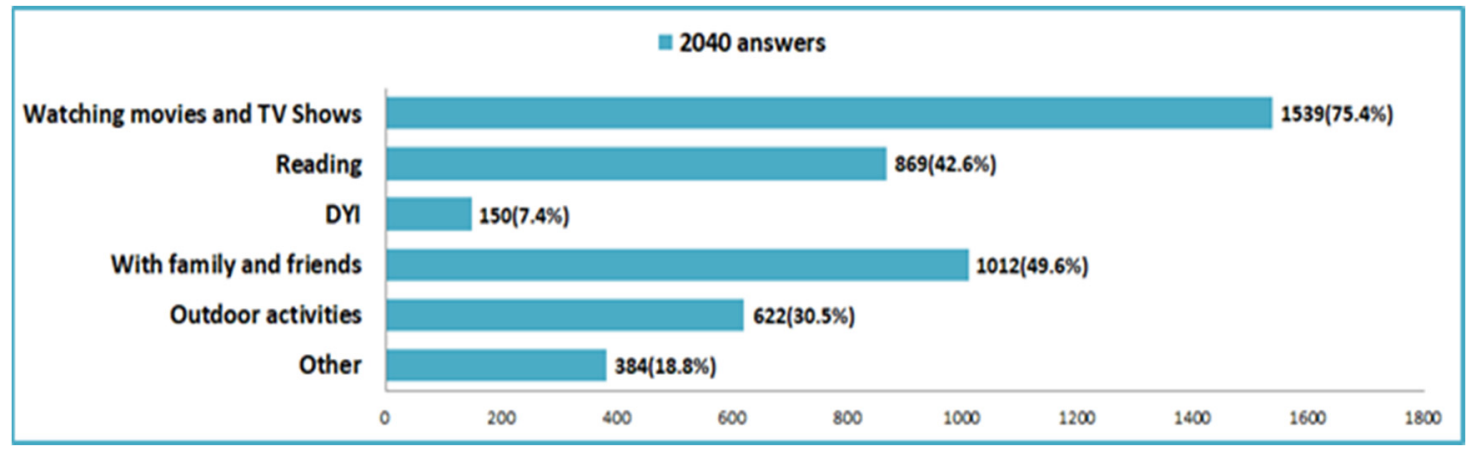

Figure 12. Ways to spend free time in the pandemic period.

\section{Discussion}

The COVID-19 pandemic brought significant changes in people's lifestyle, diet, and in psycho-emotional behavior. However, on the other hand, the fear for one's own health and those close to oneself determined the closer monitoring of one's health, paying more attention to the quality and nutritional value of food, and also to personal hygiene.

The interest in purchasing fresh fruits and vegetables during the COVID-19 pandemic, as an improvement in nutritional habits, was also highlighted by similar studies carried out in Romania, Italy and Spain. Up to $40 \%$ of the respondents stated they had a significant increase in their intake of heathy foods, with positive effects on tone and health $[45,46]$. Additionally, the studies revealed that the adult population is yet far from attaining, and moreover preserving, healthy eating behaviors. Permanent eating habits are difficult to maintain and there is still a great share of the population that did not report positive consequences in eating behavior.

The viral infection and its consequences are just part of the negative impact of the COVID-19 pandemic. Changes in eating habits related to lockdown, leading to increased intake of sugars, fats, and salt, and also overeating in response to negative feelings, were observed by studies carried out in different countries $[47,48]$.

If in countries with a Mediterranean diet such as Italy and Spain it was found that during the pandemic the population paid special attention to the nutritional quality of food [49,50], realizing the need to improve the diet to strengthen the immune system, the Romanian population needs to improve both nutrition and lifestyle. The present study found a low consumption of vegetables and fruits, well below the ratio recommended by nutritionists, namely a daily consumption of three servings of vegetables and two servings of fruits. The majority of respondents who were accustomed to eating vegetables and fruits daily stated that the ration was one serving per day. Additionally, regarding the consumption of fish or seafood, the data of the study indicated a very low consumption trend, with most of the respondents stating that they usually consumed these foods very rarely or not at all. Nutritionists recommend consuming 2-3 servings of fish or seafood per week [51,52].

One solution would be to implement educational programs in the field of nutrition in schools and universities, as well as to intensify campaigns to promote a healthy lifestyle in the media. However, we note that nutritional counseling is needed to increase the population's focus on a healthy lifestyle to strengthen immune function and prevent metabolic disorders. In general, people are aware of the need to improve the quality of food, but the application in practice is deficient.

In terms of lifestyle improvement, there is a need to implement programs to combat sedentary lifestyles. The pandemic has generally restricted the possibility of playing sports in gyms [53], but the data collected in this study show a reduced tendency to practice 
sports both before and during the pandemic. This is all the more worrying as the vast majority of respondents were young and active people. According to the rules of healthy living, it is recommended to practice a minimum of thirty minutes of physical exercise daily. A sedentary lifestyle has now become one of the major causes of obesity and its implications [54].

The restriction of freedom of movement led to social distancing, nervousness, anxiety, depression, and compulsive eating for some people, and therefore to the depreciation of the quality of life. Many people do not realize that they need specialized care for their worsening psycho-emotional state and health.

There is a need for counseling and help for vulnerable people to cope with the new changes, in the current context.

The deterioration of the psycho-emotional state caused by the perceived pandemic in the present study is also highlighted by numerous other similar studies undertaken in various regions of the world [55,56].

From the data collected based on the questionnaire, we found that there was a deterioration of the psycho-emotional state among the respondents caused by the pandemic. Given that the majority of respondents came from the working population, we can draw attention to the need for specialist support, especially in companies with many employees and in universities, to improve mental health, as indicated by similar articles [57-59].

The pandemic period also brought significant changes in the way we spend our free time, the vast majority of respondents stating that they usually spend their free time watching $\mathrm{TV}$, and in terms of how they spend their vacation, with almost half saying that they have not traveled.

A lower vaccination rate at national level as well as a reduced adherence to a healthy diet and a reduced tendency to periodically assess the state of health among the Romanian population are one of the important causes that have led to an increase in the mortality rate for infections caused by SARS-CoV-2 virus compared to other European countries [18]. Many patients have stayed at home without contacting a health care professional until the aggravation of the disease. It is necessary to implement educational programs in the medical field at the national level in order to raise awareness among the population of the importance of a healthy lifestyle, a balanced diet and regular monitoring of health to prevent metabolic disorders, strengthen the immune system and functioning of the body in optimal conditions.

The limitations of the study: Although the distribution of the questionnaire did not limit the participation only for persons under 18 years of age, in the sample surveyed the percentage of males and persons over 65 years of age was quite low. In the case of the elderly, the reduced participation is explained by the fact that the dissemination of the questionnaire was carried out among active people through institutional emails. Regarding the low percentage of male respondents, an explanation could be their lower availability to complete the questionnaire.

\section{Conclusions}

In the present study, which included 2040 respondents, we analyzed several aspects of daily habits among the population of Romania during one year of the pandemic, compared with the period before. The respondents were mainly from the active population, especially young students or employees in private companies. Following data processing, a number of important changes were found, some with a positive impact, and others with a negative impact.

Positive impacts: The increase in home cooking and healthy food consumption, especially vegetables and fruits. Increased attention to the health and well-being of those close to them.

Negative impacts: Increased incidence of overweight or obese, and the limitation of human interactions with psychological consequences. Some respondents declared sleep problems, depression, anxiety, fatigue, increased alcohol consumption, cigarette smoking 
or compulsive eating. The overloads of the health system have also generated a limitation of the population's access to basic medical services.

Author Contributions: Conceptualization, V.N. and M.M.; methodology, M.G.; software, T.I.S.; validation, M.M., D.I.U. and N.D.G.; formal analysis, D.D.; investigation, S.M.N.; resources, C.E.D.-P.; data curation, G.S.; writing_-original draft preparation, M.M.; writing—review and editing, E.O.; visualization, D.I.U.; supervision, G.S.; project administration, V.N. and M.M.; funding acquisition, S.M.N. and E.O. All authors have read and agreed to the published version of the manuscript.

Funding: This research received no external funding.

Institutional Review Board Statement: Not applicable.

Informed Consent Statement: Not applicable.

Data Availability Statement: Not applicable.

Conflicts of Interest: The authors declare no conflict of interest.

\section{Appendix A}

Questionnaire regarding changes in lifestyle and eating habits of Romanian population during COVID-19 Pandemic

Personal data

1. Please mention your age (in years):

2. Please mention your gender:

Male

Female

3. Please mention your place of current residence:

Town

Commune/Village

4. Please mention your employment status during the pandemic:

Unemployed

Socially assisted

Retired

Student

Housewife

I'm going to work as usual

Working from home

Hybrid work (teleworking and commuting)

I had my job temporarily suspended due to the pandemic

Anthropometric data

5. Please state your weight (in $\mathrm{kg}$ ):

6. Please mention your height (in $\mathrm{cm}$ ): Current eating habits:

7. What is the main type of dietary fat used?

Sunflower oil

Olive oil

Lard

Butter

Margarine

8. How many servings of vegetables (approx. $100 \mathrm{~g}$ ) do you eat each day?

Very rarely or not at all

One

Two 
Three

More than three

9. How many servings of fruit (approx. $100 \mathrm{~g}$ ) do you eat each day?

Very rarely or not at all

One

Two

Three

More than three

10. How often do you eat meat?

Very rarely or not at all

Daily

Once a week

Twice a week

More than two times a week

11. How often do you consume carbonated or sweetened beverages $(1$ serving $=330 \mathrm{~mL}$, a glass)?

Very rarely or not at all

Daily

Once a week

Twice a week

More than 2 times a week

12. How often do you drink alcohol ( 1 glass of wine $=125 \mathrm{~mL}, 1$ glass of spirit $=50 \mathrm{~mL})$ ?

Very rarely or not at all

One serving daily

More than one serving a day

Once a week

Twice a week

More than 2 times a week

13. How often do you eat fish or seafood?

Very rarely or not at all

Daily

Once a week

Twice a week

More than 2 times a week

14. How often do you consume sweets/pastries?

Very rarely or not at all

Daily

Once a week

Twice a week

More than 2 times a week

15. How often do you eat pasta, rice or other cereals?

Very rarely or not at all

Daily

Once a week

Twice a week

More than 2 times a week

16. How much bread do you eat each day?

Very rarely or not at all 4 slices 
$5-7$ slices

8-12 slices

More than 12 slices

17. How often do you consume dairy products?

Very rarely or not at all

Daily

Once a week

Twice a week

More than 2 times a week

18. How many eggs do you eat per week?

Very rarely or not at all

$1-2$ eggs

3-5 eggs

More than 5 eggs

19. Did you change your lifestyle and eating habits during the pandemic?

Not

Yes, they got worse

Yes, they improved

20. Which of these foods and beverages have you been consuming more during the pandemic, than before?

Fresh fruits and vegetables

Pasta and cereals

Homemade bread/homemade pizza/homemade pastries

Commercial bakery products

Fast food products

Snacks

Sweets

Ham and processed meat (sausages)

Dairy products/cheese/milk and yogurt

Eggs

Fish/seafood

Frozen products

Cans

Meat

Coffee/Tea

Natural juices

Sugar or sweeteners

Carbonated or sweetened non-alcoholic beverages

Alcoholic beverages: sparkling drinks/wine, beer, etc.

None

21. Which of the following foods and beverages have you been consuming less during the pandemic, than before?

Fresh fruits and vegetables

Pasta and cereals

Homemade bread/homemade pizza/homemade pastries

Commercial bakery products

Fast food products

Snacks

Sweets

Ham and processed meat (sausages)

Dairy products/cheese/milk and yogurt 


\section{Eggs}

Fish/seafood

Frozen products

Cans

Meat

Coffee/Tea

Natural juices

Sugar or sweeteners

Carbonated or sweetened non-alcoholic beverages

Alcoholic beverages: sparkling drinks/wine, beer, etc.

None

22. Have you changed the number of daily meals during the pandemic?

No

Yes, I missed one or more main meals (breakfast, lunch, dinner)

Yes, I missed one or more snacks between meals

Yes, I added one or more of the main meals

Yes, I added one or more snacks between meals

23. How much water do you drink a day?

Under $1 \mathrm{~L}$

$1 \mathrm{~L}-2 \mathrm{~L}$

Over $2 \mathrm{~L}$

Lifestyle changes

24. How do you mainly buy your food and essential products during the pandemic?

I don't go shopping, I turn to other people

Central Market/Supermarket

Grocery store near the house

Online shopping

25. Which of the following products do you most frequently buy during the pandemic?

Vegetables and fruits

Basic foods: oil, sugar, flour, rice, bread, water, pasta

Fast food products

Canned and frozen products

Meat and sausages

Fish and seafood

Alcoholic beverages

Cigarettes

Coffee

Sweets/snacks

Disinfectants/cleaning products

26. When you buy food, what matters most?

The price

Nutritional value and quality

Promotional offers

27. Do you think that during the COVID-19 pandemic you eat more than necessary?

No, I consume rationally enough

No, I eat less

Yes, I overeat

28. Do you consider that you eat healthier foods during the COVID-19 pandemic?

No, due to lack of money 
No, due to lack of food or inability to get it

No, because I haven't changed my eating behaviour at all

No, because of the fast pace of life

Yes

29. During the COVID-19 pandemic, you consumed more than before:

Home cooked food

Cold food: canned food, sausages

Food ordered and served at home

Fast food products

Pastry

30. Did you smoke before the pandemic?

No

Yes, every day

Yes, 2-3 times a week

Yes, occasionally

31. Do you currently smoke?

No

Yes, every day

Yes, 2-3 times a week

Yes, occasionally

32. How many hours a night did you usually sleep before the COVID-19 pandemic?

7-9 h a night

Over $9 \mathrm{~h}$ a night

Less than $7 \mathrm{~h}$ a night

I had frequent insomnia

33. How many hours a night you currently sleep?

7-9 h a night

Over $9 \mathrm{~h}$ a night

Less than $7 \mathrm{~h}$ a night

I have frequent insomnia

34. Did you exercise/practice sports before the COVID-19 pandemic?

No

Yes, every day

Yes, 2-3 times a week

Yes, rarely

35. During the COVID-19 pandemic do you exercise/practice sports?

No

Yes, every day

Yes, 2-3 times a week

Yes, rarely

36. Where do you exercise/play during the COVID-19 pandemic?

At home

Outdoor

Gym

I don't exercise/practice sports

37. Are you tired during the pandemic?

Yes, frequently

Yes, rarely 


\section{No}

38. Have you noticed any changes in your feeling of hunger or satiety during the pandemic?

No

Yes, I have less appetite

Yes, I have more appetite

39. Did you notice a change in weight during the COVID-19 pandemic?

No, my weight is stable

Yes, I think I lost weight

Yes, I think I gained weight

I don't know

40. Do you have anxiety during the pandemic?

Yes, frequently

Yes, rarely

No

41. Did you have anxiety before the COVID-19 pandemic?

Yes, frequently

Yes, rarely

No

42. Have you been feeling depressed during the pandemic?

Yes, frequently

Yes, rarely

No

43. Had you been feeling depressed before the COVID-19 pandemic?

Yes, frequently

Yes, rarely

No

44. Have you been experiencing nervousness, irascibility during the pandemic?

Yes, frequently

Yes, rarely

No

45. Were you nervous before the COVID-19 pandemic?

Yes, frequently

Yes, rarely

No

46. Do you need the advice of a psychologist or psychiatrist during the pandemic?

Yes

No

47. How do you think the quality of life changed during the pandemic?

It improved

It depreciated due to declining revenues

It depreciated due to job loss

It depreciated due to social distancing

It has deteriorated due to impaired health

It hasn't changed at all 
48. What did you miss most during the pandemic?

Freedom of movement

Access to quality food

Access to medical services

Communication with loved ones

Nothing

49. Have you been infected with COVID-19?

Yes

No

I don't know

50. Have you self-isolated (quarantined) due to COVID-19 infection?

Yes

No

I was not infected with COVID-19

51. Have you had the flu shot in the last 6 months?

Yes

No

52. Did you get the vaccine against COVID-19?

Yes, a dose

Yes, one dose but I refused the second dose

Yes, two doses

No, because I didn't have access to it

No, because I don't want to get vaccinated right now

53. Were you satisfied with the quality of medical services during the pandemic?

No, I was dissatisfied with the quality of medical services

No, I was unhappy with the limited access to medical services

Yes, I was satisfied with the quality of medical services

I did not need medical services during the pandemic

I avoided access to medical services during the pandemic even though I needed to

54. What do you think are the most important changes caused by the COVID-19 pandemic on your lifestyle?

I consider that I have started to adopt a healthier lifestyle, I rest more, I eat healthier I monitor my health more closely

I became more sympathetic with people around me

I isolated myself from those around me

My health has been deteriorated

The quality of life has been deteriorated

Nothing changed during the pandemic

55. Are you afraid of COVID-19 infection?

Yes, I'm afraid for those close to me

Yes, I'm afraid for my health

I'm not afraid at all

56. What type of chronic conditions do you have? (several variants)

Hypertension

Cardiovascular diseases

Diabetes

Obesity

Lung diseases 
Kidney disease

Autoimmune diseases

Gastric disorders

Liver disease

Other

I'm clinically healthy

I don't know

57. How did you spend your free time during the pandemic?

Watching movies and TV shows

Reading

DIY

With family or friends

Outdoor activities

Other

58. Did you leave for vacations during the pandemic?

Yes, as usual

Yes, more than before the pandemic

Yes, less than before the pandemic

\section{References}

1. Baldwin, R.; Weder di Mauro, B. Introduction. In Economics in the Time of COVID-19; Baldwin, R., Weder di Mauro, B., Eds.; CEPR Press: London, UK, 2020.

2. $\quad$ Eichenbaum, M.S.; Rebelo, S.; Trabandt, M. The Macroeconomics of Epidemics; NBER Working Paper Series; Working Paper 26882; National Bureau of Economic Research: Cambridge, MA, USA, 2020. Available online: https://www.nber.org/papers/w26882 .pdf (accessed on 4 October 2021).

3. World Bank. Europe and Central Asia Economic Update, Spring 2020: Fighting COVID-19; World Bank: Washington, DC, USA, 2020; (C) World Bank. License: CC BY 3.0 IGO. Available online: https://openknowledge.worldbank.org/handle/10986/33476 (accessed on 4 October 2021).

4. ILO. Monitor 1st Edition, COVID-19 and the World of Work: Impact and Policy Responses, 18 March 2020. Available online: www.ilo.org (accessed on 4 October 2021).

5. ILO. Social Protection Responses to the COVID-19 Crisis around the World: Updated on 06 April 2020. Available online: https:/ / www.ilo.org (accessed on 6 October 2021).

6. IMF. World Economic Outlook, April 2020: Chapter 1. Available online: https://www.imf.org (accessed on 6 October 2021).

7. Gadermann, A.C.; Thomson, K.C.; Richardson, C.G.; Gagne, M.; McAuliffe, C.; Hirani, S.; Jenkins, E. Examining the impacts of the COVID-19 pandemic on family mental health in Canada: Findings from a national cross-sectional study. BMJ Open 2021, 11, e042871. [CrossRef]

8. Lancet Child Adolescent Health. Pandemic school closures: Risks and opportunities. Lancet Child Adolesc. Health 2020, 4, 341. [CrossRef]

9. Bradbury-Jones, C.; Isham, L. The pandemic paradox: The consequences of COVID-19 on domestic violence. J. Clin. Nurs. 2020, 29, 2047-2049. [CrossRef]

10. Jackson, D.; Bradbury-Jones, C.; Baptiste, D.; Gelling, L.; Morin, K.; Neville, S.; Smith, G.D. Life in the pandemic: Some reflections on nursing in the context of COVID-19. J. Clin. Nurs. 2020, 29, 2041-2043. [CrossRef]

11. Biroul Regional al Fondului Naţiunilor Unite pentru Copii (UNICEF). Pentru Europa şi Asia Centrală 2020—Crearea unor Sisteme de Educaţie Reziliente în Contextul Pandemiei de COVID-19: Considerente Pentru Factorii de Decizie de la Nivel Naţional, Local şi de Unitate Şcolară. Available online: https:/ / www.unicef.org/romania / (accessed on 7 October 2021).

12. National Agency for Equal Opportunities for Women and Men. Available online: https://anes.gov.ro/?s=covid (accessed on 7 October 2021).

13. Onyeaka, H.; Anumudu, C.K.; Al-Sharify, Z.T.; Egele-Godswill, E.; Mbaegbu, P. COVID-19 pandemic: A review of the global lockdown and its far-reaching effects. Sci. Prog. 2021, 104, 00368504211019854. [CrossRef]

14. Singh, S.; Roy, D.; Sinha, K.; Parveen, S.; Sharma, G.; Joshi, G. Impact of COVID-19 and lockdown on mental health of children and adolescents: A narrative review with recommendations. Psychiatry Res. 2020, 293, 113429. [CrossRef]

15. Usher, K.; Bhullar, N.; Jackson, D. Life in the pandemic: Social isolation and mental health. J. Clin. Nurs. 2020, $29,2756-2757$. [CrossRef]

16. Rippe, J.; Foreyt, J.P. COVID-19 and Obesity: A Pandemic Wrapped in an Epidemic. Am. J. Lifestyle Med. 2021, 15, 364-365. [CrossRef] 
17. Belanger, M.J.; Hill, M.A.; Angelidi, A.M.; Dalamaga, M.; Sowers, J.R.; Mantzoros, C.S. COVID-19 and disparities in nutrition and obesity. N. Engl. J. Med. 2020, 383, e69. [CrossRef]

18. COVID-19 DATE LA ZI. Available online: https:/ / datelazi.ro/ (accessed on 11 October 2021).

19. Stults-Kolehmainen, M.A.; Sinha, R. The effects of stress on physical activity and exercise. Sports Med. 2014, 44, 81-121. [CrossRef]

20. The Association of Physicians of Indian Origin (AAPI). AAPI'S Nutrition Guide to Optimal Health Using Principles of Functional Medicine \& Nutritional Genomics Part III. 2017. Available online: https:/ /www.aapiusa.org/wp-content/uploads / 2020/04/ (accessed on 11 October 2021).

21. EFSA Panel on Dietetic Products, Nutrition and Allergies (NDA). Guidance on the scientific requirements for health claims related to the immune system, the gastrointestinal tract and defence against pathogenic microorganisms. EFSA J. 2016, 14, 4369.

22. Calder, P.C. Nutrition, immunity and COVID-19. BMJ Nutr. Prev. Health 2020, 3, 74-92. [CrossRef]

23. Calder, P.C. Feeding the immune system. Proc. Nutr. Soc. 2013, 72, 299-309. [CrossRef] [PubMed]

24. Gombart, A.F.; Pierre, A.; Maggini, S. A review of micronutrients and the immune System-Working in harmony to reduce the risk of infection. Nutrients 2020, 12, 236. [CrossRef]

25. Maggini, S.; Pierre, A.; Calder, P. Immune function and micronutrient requirements change over the life course. Nutrients 2018, 10, 1531. [CrossRef]

26. Cena, H.; Calder, P.C. Defining a healthy diet: Evidence for the role of contemporary dietary patterns in health and disease Nutrients 2020, 12, 334. [CrossRef]

27. US Department of Health and Human Services; U.S. Department of Agriculture. 2015-2020 Dietary Guidelines for AMERICANS, 8th ed.; 2015. Available online: http:/ / health.gov/dietaryguidelines/2015/guidelines/ (accessed on 11 October 2021).

28. Mititelu, M.; Stanciu, T.I.; Udeanu, D.I.; Popa, D.E.; Drăgănescu, D.; Cobelschi, C.; Grigore, N.D.; Pop, A.L.; Ghica, M. The impact of COVID-19 lockdown on the lifestyle and dietary patterns among romanian population. Farmacia 2021, 69, 1-11. [CrossRef]

29. Grivennikov, S.I.; Greten, F.R.; Karin, M. Immunity, inflammation, and cancer. Cell 2010, 140, 883-899. [CrossRef]

30. Ioniţă, A.C.; Ghica, M.; Moroşan, E.; Nicolescu, F.; Mititelu, M. In vitro effects of some synthesized aminoacetanilide n'-substituted on human leukocytes separated from peripheral blood. Farmacia 2019, 67, 684-690. [CrossRef]

31. Varlas, V.N.; Borș, R.G.; Năsui, B.A.; Mititelu, M.; Gheorghiu, A.R.A.; Pop, A.L. Key points in fertility preservation treatment strategies during covid-19 pandemic. an update on pharmacological therapies. Farmacia 2021, 69, 189-199. [CrossRef]

32. Tchounwou, P.B.; Yedjou, C.G.; Patlolla, A.K.; Sutton, D.J. Heavy metal toxicity and the environment. Exp. Suppl. 2012, 101, 133-164. [CrossRef] [PubMed]

33. Ali, H.; Khan, E.; Ilahi, I. Environmental Chemistry and Ecotoxicology of Hazardous Heavy Metals: Environmental Persistence, Toxicity, and Bioaccumulation. J. Chem. 2019, 2019, 6730305. [CrossRef]

34. Năstăsescu, V.; Mititelu, M.; Goumenou, M.; Docea, A.O.; Renieri, E.; Udeanu, D.I.; Oprea, E.; Arsene, A.L.; Dinu-Pîrvu, C.E.; Ghica, M. Heavy metal and pesticide levels in dairy products: Evaluation of human health risk. Food Chem. Toxicol. 2020, 146, 111844. [CrossRef] [PubMed]

35. Mititelu, M.; Ghica, M.; Ionita, A.C.; Moroşan, E. The influence of heavy metals contamination in soil on the composition of some wild edible mushrooms. Farmacia 2019, 67, 398-404. [CrossRef]

36. Lawshe, C.H. A quantitative approach to content validity. Pers. Psychol. 1975, 28, 563-575. [CrossRef]

37. Yusoff, M.S.B. ABC of Content Validation and Content Validity Index Calculation. Educ. Med. J. 2019, 11, 49-54. [CrossRef]

38. Deniz, M.S.; Alsaffar, A.A. Assessing the validity and reliability of a questionnaire on dietary fibre-related knowledge in a Turkish student population. J. Health Popul. Nutr. 2013, 31, 497-503. [CrossRef]

39. Hlavac, M. Stargazer: Well-Formatted Regression and Summary Statistics Tables. R Package Version 5.2.1. 2018. Available online: https: / /CRAN.R-project.org/package=stargazer (accessed on 15 July 2021).

40. Mair, P.; Wilcox, R. Robust Statistical Methods in R Using the WRS2 Package. Behav. Res. Methods 2020, 52, 464-488. [CrossRef]

41. Zhang, X.; Oluyomi, A.; Woodard, L.; Raza, S.A.; Adel Fahmideh, M.; El-Mubasher, O.; Byun, J.; Han, Y.; Amos, C.I.; Badr, H. Individual-Level Determinants of Lifestyle Behavioral Changes during COVID-19 Lockdown in the United States: Results of an Online Survey. Int. J. Environ Res. Public Health 2021, 18, 4364. [CrossRef]

42. R Core Team. R: A Language and Environment for Statistical Computing; R Foundation for Statistical Computing: Vienna, Austria, 2019. Available online: https:/ / www.R-project.org/ (accessed on 15 July 2021).

43. Branca, F.; Nikogosian, H.; Lobstein, T. (Eds.) The Challenge of Obesity in the WHO European Region and the Strategies for Response; WHO Regional Office for Europe: Copenhagen, Denmark, 2007; ISBN 9789289014083. Available online: https: / / wellcomecollection.org/works / rxvygnsr (accessed on 15 July 2021).

44. Ashwell, M.; Gibson, S. Waist-to-height ratio as an indicator of early health risk: Simpler and more predictive than using a matrix based on BMI and waist circumference. BMJ Open 2016, 6, e010159. [CrossRef]

45. Nitu, I.; Rus, V.A.; Sipos, R.S.; Nyulas, T.; Cherhat, M.P.; Ruta, F.; Nitu, C.C. Assessment of Eating Behavior During the COVID-19 Pandemic Period. A Pilot Study. J. Interdiscip. Med. 2021, 6, 67-73. [CrossRef]

46. Mignogna, C.; Costanzo, S.; Ghulam, A.; Cerletti, C.; Donati, M.B.; de Gaetano, G.; Iacoviello, L.; Bonaccio, M. Impact of Nationwide Lockdowns Resulting from the First Wave of the COVID-19 Pandemic on Food Intake, Eating Behaviors, and Diet Quality: A Systematic Review. Adv. Nutr. 2021, nmab130. [CrossRef] [PubMed] 
47. Pérez-Rodrigo, C.; Citores, M.G.; Bárbara, G.H.; Ruiz-Litago, F.; Sáenz, L.C.; Arija, V.; López-Sobaler, A.M.; Martínez de Victoria, E.; Ortega, R.M.; Partearroyo, T.; et al. Patterns of Change in Dietary Habits and Physical Activity during Lockdown in Spain Due to the COVID-19 Pandemic. Nutrients 2021, 13, 300. [CrossRef]

48. Filip, R.; Anchidin-Norocel, L.; Gheorghita, R.; Savage, W.K.; Dimian, M. Changes in Dietary Patterns and Clinical Health Outcomes in Different Countries during the SARS-CoV-2 Pandemic. Nutrients 2021, 13, 3612. [CrossRef]

49. Di Renzo, L.; Gualtieri, P.; Pivari, F.; Soldati, L.; Attina, A.; Cinelli, G.; Leggeri, C.; Caparello, G.; Barrea, L.; Scerbo, F.; et al. Eating habits and lifestyle changes during COVID-19 lockdown: An Italian survey. J. Transl. Med. 2020, 18, 229. [CrossRef] [PubMed]

50. Navarro-Pérez, C.F.; Fernández-Aparicio, Á.; González-Jiménez, E.; Montero-Alonso, M.A.; Schmidt-RioValle, J. Effects of COVID-19 lockdown on the dietary habits and lifestyle in a population in southern Spain: A cross-sectional questionnaire. Eur. J. Clin. Nutr. 2021. [CrossRef]

51. Agudo, A. Measuring Intake of Fruit and Vegetables. In Proceedings of the Joint FAO/WHO Workshop on Fruit and Vegetables for Health, Kobe, Japan, 1-3 September 2004; ISBN 9241592826. Available online: https:/ /www.who.int/dietphysicalactivity/ publications/f\&v_intake_measurement.pdf (accessed on 11 January 2022).

52. Advice about Eating Fish. Available online: https://www.fda.gov/food/consumers/advice-about-eating-fish (accessed on 11 January 2022).

53. The Impact of COVID-19 on Sport, Physical Activity and Well-Being and Its Effects on Social Development. Available online: https:/ / www.un.org/development/desa/dspd/2020/05/covid-19-sport/ (accessed on 11 January 2022).

54. Kaur, H.; Singh, T.; Arya, Y.K.; Mittal, S. Physical Fitness and Exercise During the COVID-19 Pandemic: A Qualitative Enquiry. Front Psychol. 2020, 11, 590172. [CrossRef]

55. Vuillier, L.; May, L.; Greville-Harris, M.; Surman, R.; Moseley, R.L. The impact of the COVID-19 pandemic on individuals with eating disorders: The role of emotion regulation and exploration of online treatment experiences. J. Eat. Disord. 2021, 9, 10. [CrossRef]

56. Dixit, A.; Marthoenis, M.; Arafat, S.M.Y.; Sharma, P.; Kar, S.K. Binge watching behavior during COVID 19 pandemic: A cross-sectional, cross-national online survey. Psychiatry Res. 2020, 289, 113089. [CrossRef]

57. Pedrosa, A.L.; Bitencourt, L.; Fróes, A.C.F.; Cazumbá, M.L.B.; Campos, R.G. Emotional, Behavioral, and Psychological Impact of the COVID-19 Pandemic. Front. Psychol. 2020, 11, 566212. [CrossRef]

58. Dutheil, F.; Mondillon, L.; Navel, V. PTSD as the second tsunami of the SARS-CoV-2 pandemic. Psychol. Med. 2020, 51, 1773-1774. [CrossRef] [PubMed]

59. Zaka, A.; Shamloo, S.E.; Fiorente, P.; Tafuri, A. COVID-19 pandemic as a watershed moment: A call for systematic psy-chological health care for frontline medical staff. J. Health Psychol. 2020, 25, 883-887. [CrossRef] [PubMed] 